\title{
Sublimator Driven Coldplate Engineering Development Unit Test Results
}

\author{
Rubik B. Sheth ${ }^{1}$ and Ryan A. Stephan. ${ }^{2}$ \\ National Aeronautics and Space Administration, Houston, TX, 77058 \\ Thomas O. Leimkuehler ${ }^{3}$ \\ Paragon Space Development Corporation, Houston, TX, 77058
}

\begin{abstract}
The Sublimator Driven Coldplate (SDC) is a unique piece of thermal control hardware that has several advantages over a traditional thermal control scheme. The principal advantage is the possible elimination of a pumped fluid loop, potentially increasing reliability and reducing complexity while saving both mass and power. Because the SDC requires a consumable feedwater, it can only be used for short mission durations. Additionally, the SDC is ideal for a vehicle with small transport distances and low heat rejection requirements. An SDC Engineering Development Unit was designed and fabricated. Performance tests were performed in a vacuum chamber to quantify and assess the performance of the SDC. The test data was then used to develop correlated thermal math models. Nonetheless, an Integrated Sublimator Driven Coldplate (ISDC) concept is being developed. The ISDC couples a coolant loop with the previously described SDC hardware. This combination allows the SDC to be used as a traditional coldplate during long mission phases and provides for dissimilar system redundancy
\end{abstract}

\section{Nomenclature}

$\begin{array}{ll}Q & =\text { Heat Rejection } \\ V & =\text { Voltage } \\ i & =\text { Current } \\ \Delta \mathrm{h} & =\text { Heat of Vaporization } \\ u & =\text { Sublimator Utilization } \\ \Delta \mathrm{T} & =\text { Temperature Difference } \\ \Delta \mathrm{x} & =\text { Distance Change } \\ \mathrm{k} & =\text { Conductivity } \\ \dot{m}_{a} & =\text { Actual Mass Flow Rate of Water Used By Sublimator } \\ \dot{m}_{i} & =\text { Ideal Mass Flow Rate of Water Sublimator Should Use }\end{array}$

\footnotetext{
${ }^{1}$ Project Engineer, Crew and Thermal Systems Division, 2101 Nasa Road 1 EC2

${ }^{2}$ Project Manager for Advanced Thermal Control Technologies, Crew and Thermal Systems Division, 2101 Nasa Road 1 ECl

${ }^{3}$ Senior Aerospace Engineer, 1120 NASA Parkway, Suite 505.
} 


\section{Introduction}

Space flight vehicles rely on many different methods of heat rejection. The optimal method is driven by the waste Sheat load rejection requirement of the vehicle, mission duration, and size/volume restrictions. Heat rejection hardware includes radiators, phase change material heat exchangers (PCMHX), and evaporators. Radiators and PCMHX typically trade well for long duration missions while evaporators, such as a sublimator, tend to trade well for short duration mission scenarios. An evaporator rejects the vehicle's excess heat by evaporating a consumable. A sublimator, which is a specialized type of evaporator, rejects heat by using the process of sublimation, which is when a substance, such as water, changes from a solid phase directly to the vapor phase. Conventional sublimators, such as the ones used on the Apollo Lunar Module and Extravehicular Mobility Unit, allow a consumable feedwater to freeze and then sublimate, with the energy required for phase change provided by the warm coolant flowing through the sublimator.

The Sublimator Driven Coldplate (SDC) is an evolutionary step forward from conventional sublimator designs. The SDC design couples the energy source, such as computers or avionics boxes, directly to the sublimator. This simply means that the heat source is conductively attached to the sublimator. A simplified example showing the difference between a traditional sublimator and SDC is shown in Figure 1. The SDC design has no moving parts and no power is required. This, in turn, eliminates the need for a pumped fluid loop and results in significant thermal control system mass reductions on a space flight vehicle. Initial mass trades have shown a mass reduction of nearly $25 \%$ for the Altair Lunar Lander's Ascent Module thermal control system mass.
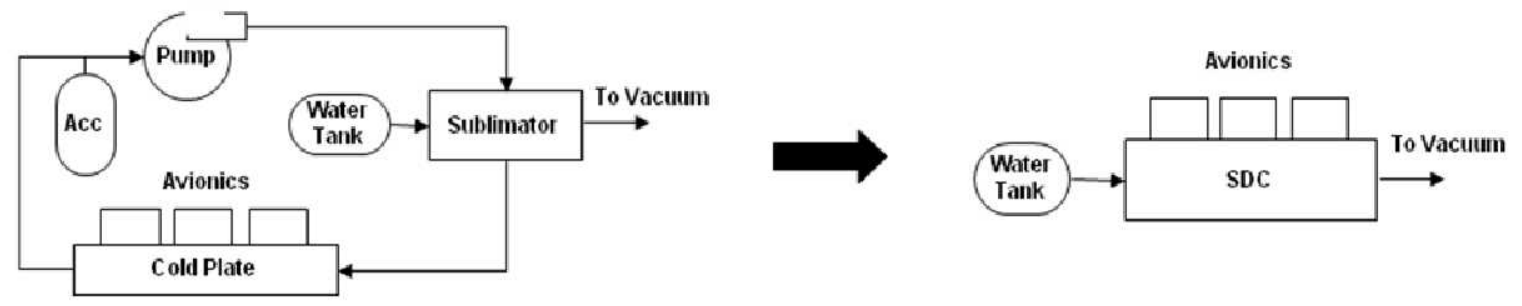

\section{Figure 1. Difference Between Traditional Thermal Control System incorporating a Sublimator and the Novel Sublimator Driven Coldplate.}

NASA JSC personnel designed and fabricated SDC coupons which were used to provide proof of concept studies and to evaluate contractor SDC designs. The coupon design and a breakdown of the coupon architecture are shown in Figure 2. See last year's ICES paper, Testing and Model Correlation of Sublimator Driven Coldplate Coupons and EDU, for a description of the coupon test article design. The coupon level tests proved the feasibility of the SDC concept and demonstrated SDC design limitations ${ }^{1}$. The tests also exposed the importance of eliminating localized regions of high heat fluxes. A high heat flux concentration leads to feedwater breakthrough, which significantly reduces the SDC feedwater consumption efficiency (or utilization). Based on empirical data from the coupon test program, a contractor was selected to design and build a SDC Engineering Development Unit (EDU). The current paper will present the SDC EDU test results and the subsequent thermal math model that was used to better understand the test results. 

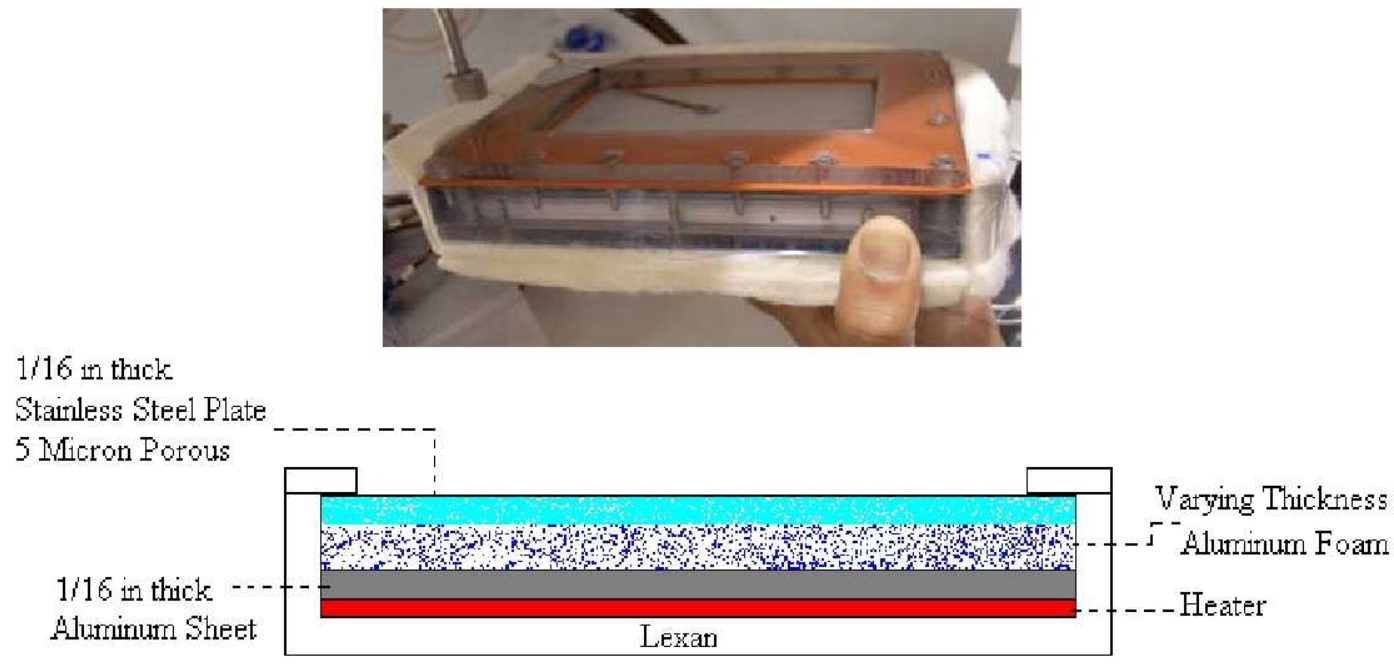

Figure 2. Sublimator Driven Coldplate Coupon Design

\section{Experimental Investigation}

\section{A. SDC EDU Test Article}

The Sublimator Driven Coldplate EDU design is a small scale version of a proposed SDC prototype developed by one of the contractors. The selected design incorporates a novel idea to mitigate risks associated to localized heat fluxes observed during the aforementioned coupon testing. The EDU shown in Figure 3 is 6" 6 6" $\mathrm{x} 2$ ". Feedwater enters the SDC EDU through 1/4" tubing and fills a feedwater reservoir. The feedwater reservoir is sandwiched by two mounting plates and is filled with aluminum foam. The aluminum foam reduces the thermal resistance between the coldplate surface and sublimation surface. Furthermore, the aluminum foam also helps with improving the structural stability of the SDC EDU. The sublimation surface is comprised of three five-micron, one-inch diameter, porous stainless steel tubes spaced equally apart. These tubes are essentially the same porous sheets used during coupon level tests, but are cylindrical which reduces the potential for high localized heat fluxes. The SDC design requirement was to maintain a coldplate temperature below $40^{\circ} \mathrm{C}$ when exposed to a uniform heat flux of $2 \mathrm{~W} / \mathrm{in}^{2}$. To better understand the SDC performance, the test matrix included test points with applied fluxes up to $10 \mathrm{~W} / \mathrm{in}^{2}$. As shown in Figure 4, the SDC EDU was instrumented with eight thermocouples.

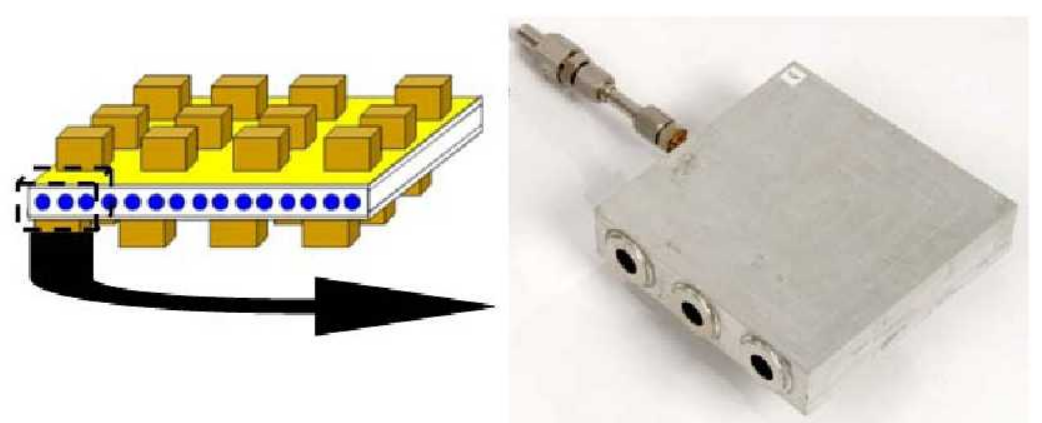

Figure 3. Sublimator Driven Coldplate Engineering Development Unit 

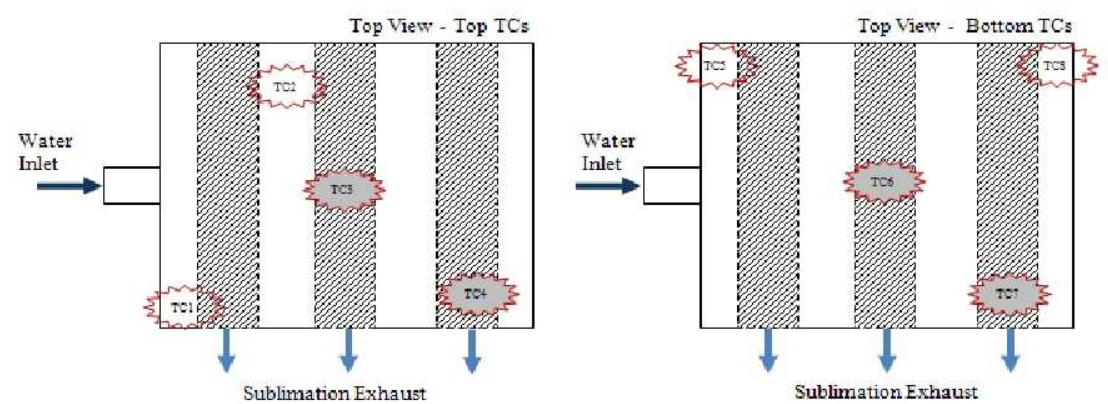

Figure 4. Sublimator Driven Coldplate EDU TC Placement

\section{B. Test Loop Architecture}

Figure 5 shows the feedwater loop and the location of the test article in the vacuum chamber. Deionized and degassed water is supplied from a pressurized feedwater tank. Prior to entering the sublimator, the feedwater passes through a pressure regulator, which is used to maintain the feedwater pressure at 3 psia. For diagnostic purposes, a pressure transducer is included downstream of the regulator to record the water pressure at the sublimator inlet. Furthermore, a flow meter was used to record the flow rate of the feedwater throughout the test point. For redundancy, the feedwater tank was located on a scale. Mass readings from this scale were recorded and used to calculate the sublimator's utilization. Labview was used to record all of the instrumentation and thermocouples, and to control the test article's heaters. Two heaters were used to apply a maximum, combined heat load of 540 Watts.

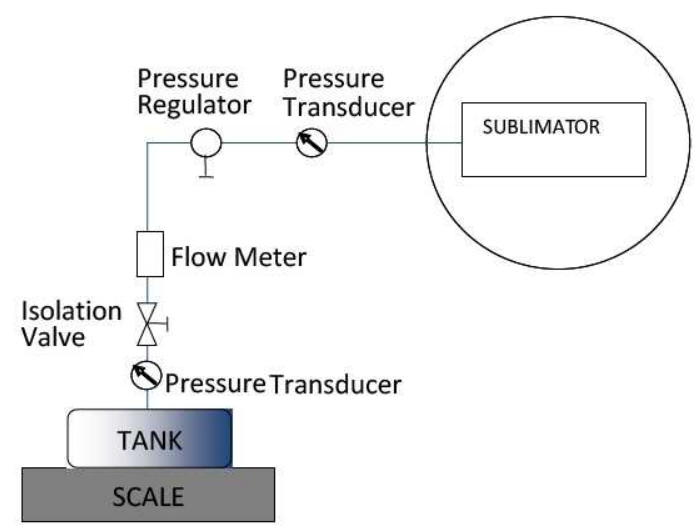

Figure 5. Sublimator Driven Coldplate Test Loop Design

The second key performance parameter derived for the sublimator test was the feedwater utilization (u). Sublimator utilization is a measurement of how efficiently the SDC used the feedwater for an applied heat load. Under ideal operating conditions, all of the feedwater supplied to the sublimator would freeze to solid ice and be sublimated to the ambient vacuum. In this situation, the ideal feedwater mass flowrate would be expressed as:

$$
\dot{\mathrm{m}}_{\mathrm{i}}=\frac{\mathrm{Q}}{\Delta \mathrm{h}}
$$

Equation 2

From Equation 2, $\Delta \mathrm{h}$ represents the change in enthalpy of the feedwater from the feedwater inlet (liquid water) to the sublimator outlet (water vapor). In order to assess the SDC feedwater efficiency, the utilization was calculated using:

$$
\mathrm{u}=\frac{\dot{\mathrm{m}}_{\mathrm{i}}}{\dot{\mathrm{m}}_{\mathrm{a}}} \quad \text { Equation } 3
$$

4

American Institute of Aeronautics and Astronautics 
In Equation 3, $\dot{\mathrm{m}}_{\mathrm{a}}$ represents the actual feedwater mass flow rate calculated using the aforementioned feedwater weight scale. If all of the feedwater was being sublimated, the utilization would be unity. A value less than one occurred when more feedwater was being sent to the sublimator than necessary to efficiently dissipate the applied heat load. Low utilizations are calculated when the feedwater is experiencing breakthrough, which is when ice penetrates the sublimator into the vacuous environment.

\section{Test Matrix and Results}

Over the course of the test program, five test points were evaluated. A uniform heat flux was applied to both sides of the test article. Heater power settings were chosen to provide an average heat flux into the porous tubes of 2, 4, 6, 8, and $10 \mathrm{~W} / \mathrm{in}^{2}$. Heat fluxes of 6 and $8 \mathrm{~W} / \mathrm{in}^{2}$ were tested twice for repeatability purposes. Furthermore, the heat flux of $2 \mathrm{~W} / \mathrm{in}^{2}$ was tested for an entire day while the other fluxes were tested for four hours each to reduce experimental uncertainty. It is important to note that data associated with $10 \mathrm{~W} / \mathrm{in}^{2}$ was deemed an outlier due to the fact that catastrophic breakthrough was experienced and the test was prematurely stopped. Nonetheless, a summary of the results can be seen in Table 1. As shown in this table, all of the calculated feedwater utilizations were near unity with experimental uncertainties on the order of $10 \%$.

Table 1 Sublimator Driven Coldplate EDU Test Points and Results

\begin{tabular}{|c|c|c|c|}
\hline $\begin{array}{c}\text { Heat Flux } \\
\text { (W/in2) }\end{array}$ & $\begin{array}{c}\text { Coldplate } \\
\text { Temp }\left({ }^{\circ} \mathrm{C}\right)\end{array}$ & Utilization & Uncertainty \\
\hline 2 & 8.9 & $105 \%$ & $9 \%$ \\
\hline 4 & 19.1 & $106 \%$ & $8 \%$ \\
\hline 6 & 29.4 & $112 \%$ & $9 \%$ \\
\hline 6 & 30.1 & $113 \%$ & $13 \%$ \\
\hline 8 & 58.1 & $101 \%$ & $10 \%$ \\
\hline 8 & 56.0 & $111 \%$ & $13 \%$ \\
\hline
\end{tabular}

The SDC was required to maintain a coldplate temperature of no more than $40^{\circ} \mathrm{C}$ at a uniform applied heat flux of $2 \mathrm{~W} / \mathrm{in}^{2}$., which corresponds to an average heat flux of $2.6 \mathrm{~W} / \mathrm{in}^{2}$ into the porous tubes. Figure 6 shows the relationship between surface temperature and the average heat flux into the porous tubes.. The reported temperatures correspond to the hottest thermocouple data, thermocouple 6 in Figure 4, averaged over a steady state time interval. The EDU performed will within the allowable design limit, with an interpolated coldplate temperature of approximately $11^{\circ} \mathrm{C}$ at an average heat flux of $2.6 \mathrm{~W} / \mathrm{in} 2$ into the porous tubes.

The data points in pink (square symbols) are repeatability test points performed on different days. Notice that the surface temperature is increasing linearly with the heat flux for fluxes up to $6 \mathrm{~W} / \mathrm{in}^{2}$. The linearity in coldplate temperature up to $6 \mathrm{~W} / \mathrm{in}^{2}$ is attributed to the fact that the ice/water interface location is not changing much when the heat flux is increased. Another sublimator study shows that the ice layer does not change much at low applied heat fluxes. ${ }^{2}$ This relationship can be explained by examining Fourier's Law for conduction (the dominant mode of heat transfer is conduction) shown in Equation 4. For the low applied fluxes, the distance ( $\Delta \mathrm{x}$ in Equation 4$)$ between the maximum measured surface temperature and the ice/water interface is not changing. In addition, the effective thermal conductivity is not a function of the applied heat flux. Resultantly, the temperature difference between the surface temperature and the ice/water interface is linearly proportional to the applied heat flux. Because the ice/water interface is a constant $0^{\circ} \mathrm{C}$, the baseplate temperature is linearly proportional to the applied flux

$$
\Delta T=\frac{q \cdot \Delta x}{k} \quad \text { Equation } 4
$$

Due to the fact that sublimators require a consumable feedwater, it is of utmost importance that the feedwater is efficiently consumed. As mentioned above, the best way to determine the efficiency of the SDC is to calculate the utilization for any given test point. The utilization is defined as the ratio of the ideal feedwater flowrate to the actual feedwater flowrate (see Equation 3). 


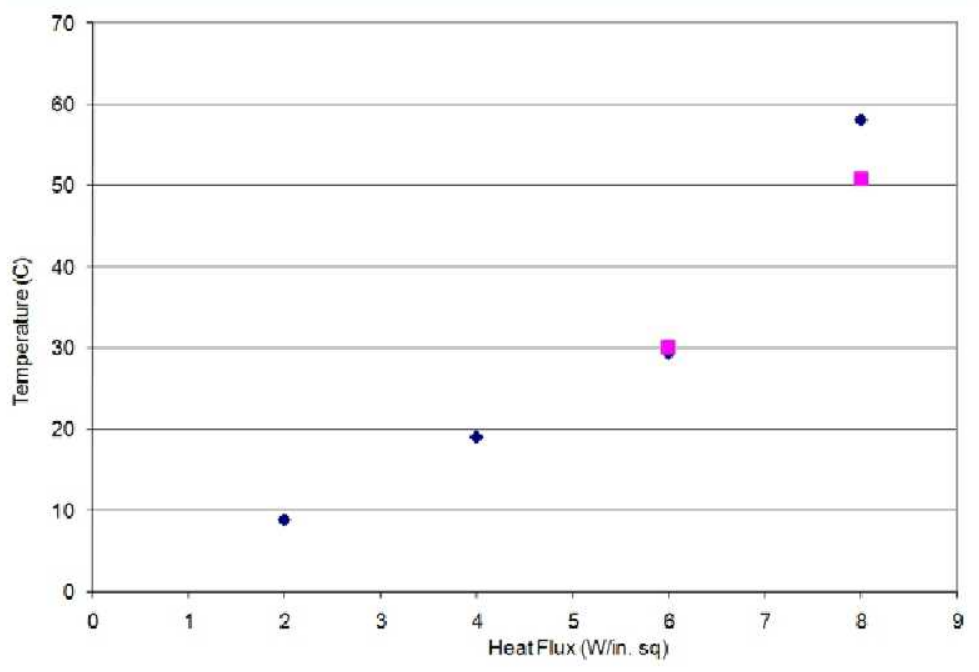

Figure 6. Sublimator Driven Coldplate EDU Coldplate Temperatures at Various Heat Fluxes

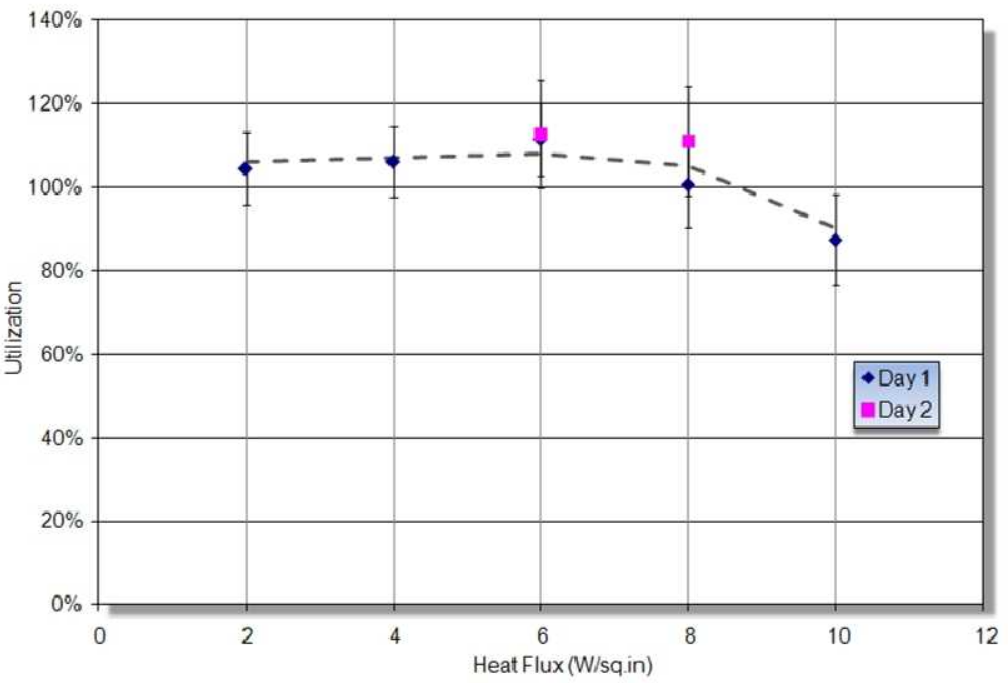

Figure 7. Sublimator Driven Coldplate EDU Utilization as a function of Applied Heat Fluxes

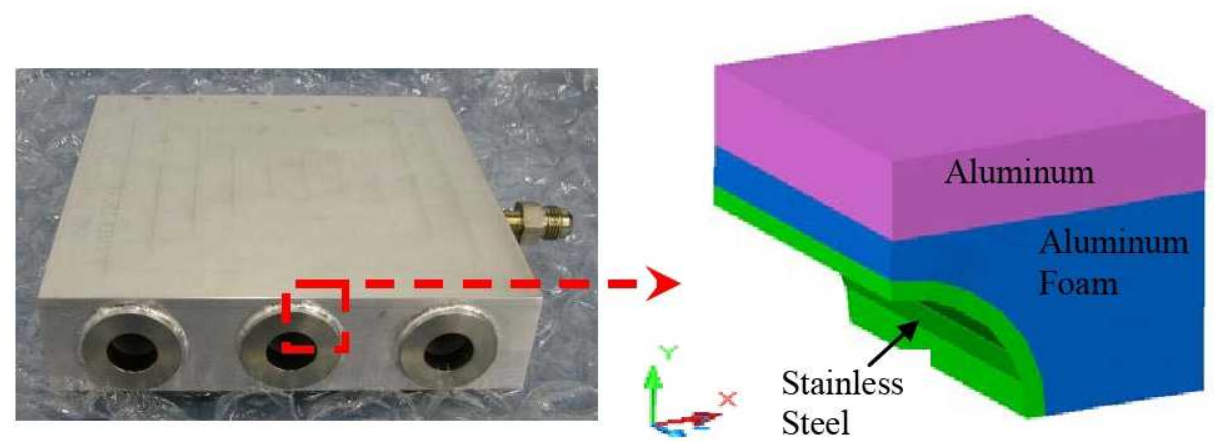

Figure 8. Sublimator Driven Coldplate EDU 1/4 Porous Tube Thermal Desktop Layout
Figure 7 is a graphical summary of the SDC EDU utilizations at various heat fluxes. In studying Figure 6, a drop-off in utilization can be seen after a heat flux of $8 \mathrm{~W} / \mathrm{in}^{2}$. Moreover, when the EDU was subjected to an applied heat flux of $10 \mathrm{~W} / \mathrm{in}^{2}$, catastrophic breakthrough was experienced resulting in utilization well below $100 \%$. In all, the SDC EDU performed considerably well up to $8 \mathrm{~W} / \mathrm{in}^{2}$, well beyond the design requirement

\section{Thermal Math Model}

\section{A. Thermophysical Properties and Boundary Conditions}

A three dimensional model of a quarter section of the sublimation tube was generated using Thermal Desktop ${ }^{\circ}$. This model was correlated using test data and used to understand the nonlinear relationship between surface temperature and applied heat fluxes above $6 \mathrm{~W} / \mathrm{in}^{2}$. A representation of this model is shown in Figure 8. The magenta section represents the aluminum coldplate surface, the blue section is the aluminum foam/water section representing the feedwater reservoir, and the green area is the porous stainless steel tube. Moreover, three boundary conditions were applied to the model. A constant $0^{\circ} \mathrm{C}$ temperature condition was applied within the stainless steel surface, a varying uniform heat flux was applied to the top aluminum surface, and an adiabatic boundary was applied to all remaining surfaces. The $0^{\circ} \mathrm{C}$ boundary depth was varied into the stainless steel sheet and feedwater reservoir for the different applied heat fluxes. Table 2 summarizes the 
of aluminum foam and water is not readily available; therefore the conductivity was found using test data at $8 \mathrm{~W} / \mathrm{in}^{2}$.

Table 2 Sublimator Driven Coldplate EDU Model Thermal Properties

\begin{tabular}{|c|c|c|}
\hline Material & $\begin{array}{c}\text { Thermal Conductivity } \\
(\mathbf{W} / \mathbf{m}-\mathbf{K})\end{array}$ & $\begin{array}{c}\text { Thickness } \\
\text { (in) }\end{array}$ \\
\hline Aluminum & 177 & 0.25 \\
\hline Water \& & 1.6 & $\begin{array}{c}0.125 \text { Top } \\
0.5 \text { Side }\end{array}$ \\
\hline Aluminum Foam & 17 & 0.0625 \\
\hline Stainless Steel & &
\end{tabular}

Table 3 Sublimator Driven Coldplate EDU Model Coldplate Temperatures and Ice Layer Location

\begin{tabular}{|c|c|c|c|}
\hline $\begin{array}{c}\boldsymbol{q}^{\mathbf{\prime}} \\
\left(\text { W/in }^{2}\right)\end{array}$ & $\begin{array}{c}\text { Coldplate Test } \\
\text { Temps }(\boldsymbol{C})\end{array}$ & $\begin{array}{c}\text { Coldplate Model } \\
\text { Temps }(\boldsymbol{C})\end{array}$ & $\begin{array}{c}\text { Location } \\
\text { of Ice (in) }\end{array}$ \\
\hline $\mathbf{2}$ & 8.9 & 9.0 & 0.125 \\
\hline $\mathbf{4}$ & 19.1 & 19.6 & 0.1146 \\
\hline $\mathbf{6}$ & 29.7 & 29.4 & 0.1146 \\
\hline $\mathbf{8}$ & 56.0 & 56.0 & 0.0521 \\
\hline
\end{tabular}

The effective thermal conductivity was changed until the model's coldplate temperature matched the test data, resulting in a value of $1.6 \mathrm{~W} / \mathrm{mK}$. This value closely matched a value found in the literature ${ }^{2}$, and was then carried through for the remainder of the modeling effort.

\section{B. Thermal Math Model Results}

The thermal math model was run for all of the applied fluxes included in the test matrix. Along with the heat flux, the ice-water interface location within the SDC model was changed so that the modeled coldplate temperature matched the coldplate temperature seen during test. The resulting coldplate temperatures were a strong function of the location of the ice/water interface.. For low heat fluxes, the interface was closer to the coldplate while at a higher heat flux the interface was farther from the coldplate and closer to the vacuous environment. This relationship was also explored and discussed by Chapman ${ }^{2}$. A summary of the coldplate temperature and ice/water interface location with respect to the applied heat flux is shown in Table 3. The location of the ice/water interface is measured from the exterior stainless steel surface to the inside of the SDC towards the feedwater reservoir. Figure 9 is a visual demonstration of how this ice growth occurs. Figure 10 is a comparison of the ice/water interface location and the test coldplate temperatures plotted with respect to the applied heat flux. It can be seen how from 2 to $6 \mathrm{~W} / \mathrm{in}^{2}$ the interface location stays fairly constant resulting in a linear increase in coldplate temperatures as discussed in the previous section. On the other hand, when the interface location from the vacuous environment decreases, the result is a non-linear increase in coldplate temperature from 6 to $8 \mathrm{~W} / \mathrm{in}^{2}$. When comparing this relationship to Equation 4 , one can see how for a fixed heat flux and conductivity, temperature is dependent on the thickness, or distance between the heat load and cooling surface.

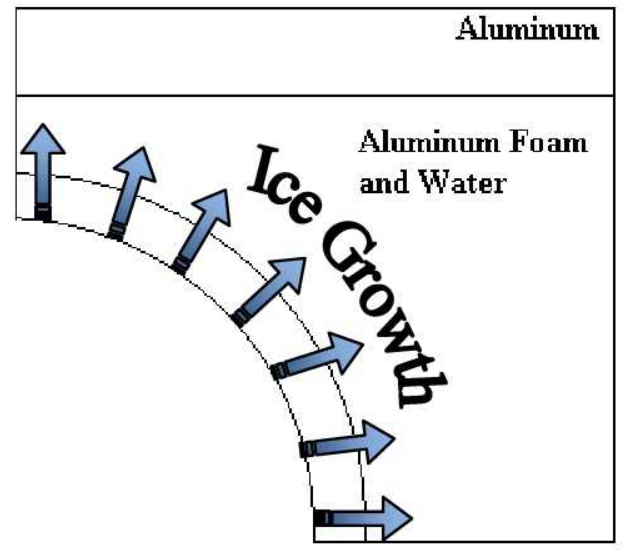

Stainless Steel

Figure 9. Diagram of How Ice Grows from the Exterior Surface of the Stainless Steel Porous Plate into the SDC. 

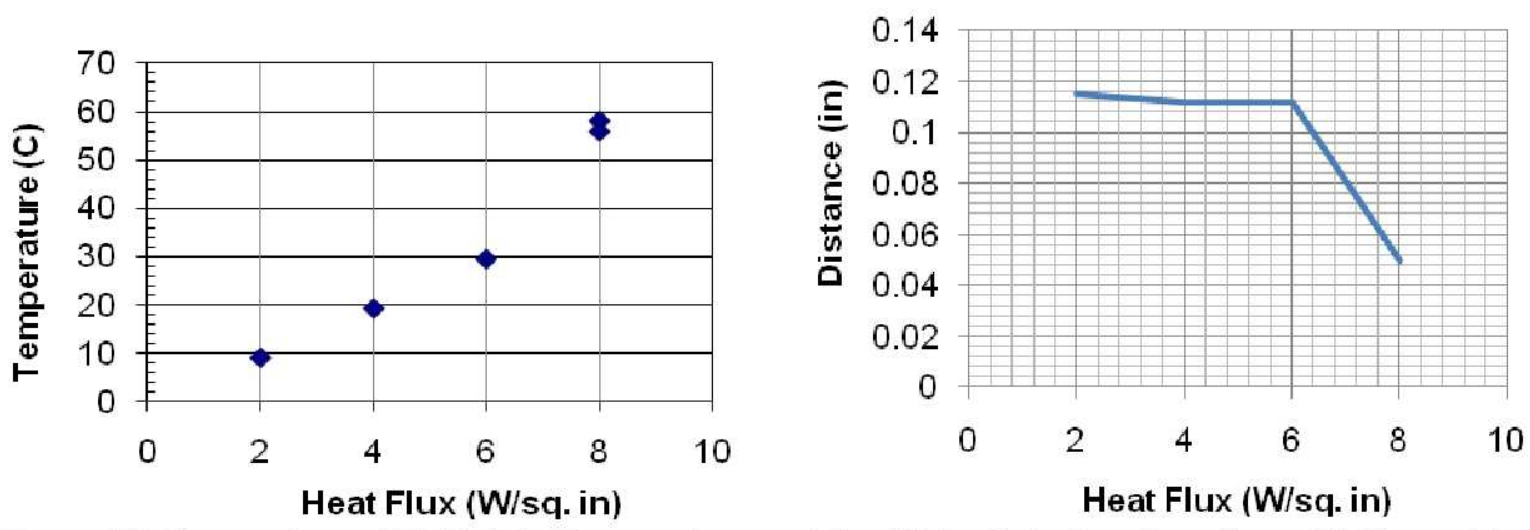

Figure 10. Comparison of Coldplate Temperature and Ice-Water Interface Location with Respect to Heat Flux

\section{Future Work}

As currently developed, the SDC design seeks to provide significant mass savings over a traditional pumped fluid loop by combining the functions of a coldplate and a sublimator so that the fluid loop could be eliminated. A target application is to provide heat rejection for the ascent module of the Altair ${ }^{3}$ lunar lander vehicle during the lunar ascent mission phase. However, in order to provide heat rejection for the ascent module during the rest of the mission, it is desirable to keep the ascent module integrated with the fluid loop in the rest of the Altair vehicle. Therefore, an Integrated Sublimator Driven Coldplate (ISDC) that can function as both a standard flow-through coldplate and a Sublimator Driven Coldplate is currently being investigated. With this integration, the radiator on the external TCS loop of the descent module can provide heat rejection during most of the mission, while the ISDC can provide heat rejection for the ascent module during lunar ascent (after the rest of the vehicle has been jettisoned). The ISDC builds on the original SDC concept by adding coolant layers so that it can be integrated with the pumped fluid loop on the rest of the vehicle. This approach provides mass savings by (1) combining multiple pieces of hardware into a single piece of hardware and (2) providing additional fault tolerance without the need for redundant hardware.

\section{Conclusion}

The Sublimator Driven Coldplate is a novel extension sublimator technology. It employs the idea of coupling a source of waste energy directly to a heat rejection device, such as the sublimator, to reject the heat. This idea of essentially coupling the coldplate to the sublimator may result in significant mass reductions for advanced thermal control system designs. This technology has the potential to reduce the Altair Ascent Module thermal control system mass by approximately $25 \%$. The unique design of the Sublimator Driven Coldplate Engineering Development Unit resulted in a design that far surpassed the design requirements. Furthermore, correlated thermal math modeling of the SDC helped to demonstrate the relationship between the applied flux and the location of the ice layer in the SDC design. Because the SDC surpassed its design requirements, improvements can be made in decreasing the reservoir volume of water within the SDC, in turn decreasing the weight of the SDC. Another design improvement currently being investigated includes the addition of a coolant passage to the SDC design. This will allow for a dissimilar source of redundancy to the SDC design. Furthermore, a coolant loop will allow for integration of the SDC to thermal control systems that require an active thermal control system incorporating radiators for space flight operations. This development effort has paved the way to further development of the SDC concept for use in NASA's planned exploration vehicles.

\section{Acknowledgments}

The authors would like to thank Osama Abounsar and Gary Noyes from Oceaneering for their contributions to the Sublimator Driven Coldplate EDU development effort. 


\section{References}

${ }^{1}$ R.Sheth, R. Stephan, T. Leimkuehler. Testing and Model Correlations of Sublimator Driven Coldplate Coupons and EDU. ICES 2009-01-2479.

${ }^{2}$ A. J. Chapman. A Fundamental Study of Sublimation through a Porous Surface, Final Report, Contract

NAS 9-7969, July 1971

${ }^{2}$ R.Stephan. Overview of Altair Lunar Lander Thermal Control System Design. ICES 2009- 